\title{
Role of private sector for HRH (Human Resource for Health) production in Nepal
}

Dixit H

Hemang Dixit, Professor, Head, Medical Education Department, Kathmandu Medical College Teaching Hospital, Kathmandu, Nepal

\section{Abstract}

Human Resource for Health production was started in Nepal in a limited way some eighty years ago and picked up a somewhat faster pace from the 1950 s as per the requirements at that time. The establishment of the Institute of Medicine led to some diversification but it was only after 1990 that there has been a much larger involvement of the private sector in the production of Human Resources for Health. Although a number of categories have been listed in this article, the position of doctors, dentists and nurses has been dealt with in more detail.

The information provided from relevant councils and some non-governmental organisations regarding the numbers produced and working in Nepal has been quoted. Not much information is available regarding the Nepalis working out of the country.

Key words: BPKIHS, CTEVT, HRH, IoM, KU, NAMS, NMC, NNC, PAHS, PC.

\section{INTRODUCTION}

The history of the development of Human 1 Resource for Health (HRH) in Nepal has to start with the establishment of the Nepal Rajakiya Ayurvedic Vidhyalaya in 1933/34 for the training of vaidyas and of the Civil Medical School soon after for the training of compounders and dressers. Subsequently midwives, nurses and doctors went for training initially to Allahabad and later to other parts of India. Following the ushering in of democracy in Nepal in 1950 the Department of Health came into being and subsequently started the training of the Basic Level and then the Middle Level of health workers within the country. Though training of doctors within the country was thought about as early as 1963, it was only started after the Institute of Medicine (loM) came into being. Initially the training of the basic levels of health manpower such as Auxiliary Health Worker (AHW), Assistant Nurse Midwife (ANM) and nurses were all under the Ministry of Health $(\mathrm{MoH})$. Following the introduction of National Education System Plan (NESP) all educational training came under the Ministry of Education. It was only after Jana Andolan I

Address for correspondence

Hemang Dixit

Professor, Head, Medical Education Department

Kathmandu Medical College Teaching Hospital,

Sinamangal, Kathmandu, Nepal

E-mail:h2dixit@gmail.com that the $\mathrm{MoH}$ restarted various grades of $\mathrm{HRH}$ training at many institutions under its wing.

The Institute of Medicine (loM) had been established, under the National Education System Plan (NESP) in 1972 for training of the basic and middle level health workers required for the country. In 1978 the loM started training of doctors ${ }^{1}$. It may be recalled that in 1978, 1980 and 1982 the Institute of Medicine (IoM) had been prodded by World Health Organization (WHO) to conduct Health Manpower Exercises to try to find out how many categories of personnel were employed or working in Nepal and what the way ahead was. In 1975 the number of physicians was 375 and had risen to 457 by 1979 . It was in this context and with an object to forecast the number of specialists that the Nepal Government with the help of GTZ drew up a Strategic Plan for Human Resources for Health 2003 - 17 (2). No further extensive work was done till this attempt. A National Conference on HRH was conceptualised and subsequently held by Nepal Government with the support of the European Union and ten other Non-Governmental Organisations (NGOs) and International Non-Governmental Organisations (INGOs) at Kathmandu on 14-15 June 2013.

The Council for Technical, Educational and Vocational Training (CTEVT) had been established by the government in 1988 for the training of middle and basic 
level workers in various fields. After the Jana Andolan I in $1989 / 90$ and during the course of the last twenty years various private institutions of differing capabilities in many different sectors suddenly mushroomed all over the country. Their objective was to fulfil the expected shortfall in the lower levels of their particular area. Thus the production of health manpower produced in the country increased rapidly. Many employers however feel that this increase in numbers has led to a falling of standards as the manpower so trained have neither had the supervision nor an essential period of skill training in proper environments.

Over the last two decades the numbers and categories of manpower have increased appreciably. Foreign students have come to Nepal to study medicine and then returned to their home countries. Similarly Nepali students have gone elsewhere in the world to study. However, a substantial number of doctors and nurses, trained in Nepal have gone mainly to USA, UK and Australia to work. How many will return back soon and how many will do so after their years of active service abroad is not known.

The WHO in 2006 brought out a document stressing on the need to ensure adequate numbers of $\mathrm{HRH}$ for the proper delivery of health services. That the shortage of HRH is grave and needs to be looked at had been felt in Nepal. It was only after 1990 that private sector involvement was encouraged in the health field and it is as result of this that a large number of institutions for the production of $\mathrm{HRH}$ have come up (3).

Whilst the different professional councils set up by Nepal Government make it mandatory for all newly produced health professionals to register with them and collect the fees for this ardently, none has a system of follow up. Many of the registered professionals who have emigrated for good or have died still have their names published in the list of the respective councils. With more widespread use of the Internet in Nepal, a system of re-registration has been introduced but is not really effective. It should be the first concern of all the Professional Councils i.e. Medical, Ayurvedic, Nursing, Health Professionals and Pharmacy that the lists which they irregularly put out are updated and correct. This should not be a difficult job considering that regular elections are held by all of them and so updating is almost a regular affair. Once updated and correct statistics are available then only can a realistic policy be made regarding the production, deployment of $\mathrm{HRH}$ within and outside Nepal.

\section{NATIONAL HEALTH TRAINING CENTRE}

With the concept of providing an integrated community oriented health services, the $\mathrm{MoH}$ started a number of Regional Training Centres in the five different regions of the country at varying periods of time during 1982 to 1990 . These centres totalled five and were mainly responsible for training community grassroots level workers such a Maternal and Child Health Workers (MCHWs) and Village Health Workers (VHWs). Following the introduction of the National Health Policy of 1991, a National Training Co-ordination Unit was established in the Ministry of Health and Population (MoHP). Centres for training of Skilled Birth Attendants (SBAs) and MCHWs were established in various parts of the country. These training centres also gave short pre- appointment instruction to categories such as Community Medical Assistants (CMAs), AHWs and ANMs,

\section{CATEGORIES OF HEALTH MANPOWER AND THEIR DEPLOYMENT IN NEPAL}

There are many and comprehensive lists with specific job description and terms of employment which have to be compiled and put into effective use for providing good health care to the people. What one generally reads in newspapers these days is regarding absenteeism at various levels in health institutions.

As per the MoHP website www.mohp.gov.np the number and breakdown of persons employed by Nepal Government or working as volunteers in the health sector at the end of 2009/10 is as follows:

\section{HEALTH WORKERS}

Doctors

$\begin{array}{lr}\text { Paramedic / Health Assistant } & 7491 \\ \text { Village Health Worker } & 3985 \\ \text { Maternal \& Child Health Worker } & 3190 \\ \text { Pharmacist + Pharmacy Assistant } & 21+15 \\ \text { Ayurvedic Physician + Baidya } & 394+360\end{array}$

\section{HEALTH VOLUNTEERS}

$\begin{array}{ll}\text { Female Community Health Volunteer } & 53999 \\ \text { Trained Traditional Birth Attendant } & 14951\end{array}$

The MoHP is the largest government ministry employing the largest number. The 28,000 in 2060 BS has now reached 31,628 , but of this there are about 4,000 vacancies. Somehow or the other there always seems to be a shortage in the government health institutions. 
One reads in the papers of shortage of ANMs, AHWs, Health Assistants (HAs) and doctors periodically. This is very ironic considering that Health Rights of every Nepali as a birth right is going to be incorporated in our constitution.

Many categories of $\mathrm{HRH}$ are produced by the Private Sector under the supervision of CTEVT which itself was under the MoE. They are in the fields of Nursing, General Medicine, Dentistry, Pharmacy and Ophthalmology workers in many CTEVT affiliated institutions. Except for two, all the others are private ones, conducting various types of programmes to produce Basic and Middle level health workers as follows:

\section{BASIC LEVEL}

(a) CMA being produced in 74 institutions and 44 producing ANMs.

\section{MIDDLE (PCL) LEVEL}

(a) - For Nursing Certificate Level - 104 institutions.

(b) - For Health Assistant level training - 47 institutions

(c) - For Laboratory Technicians - 21 institutions

(d) - For Pharmacy Assistants - 44 institutions.

(e) - For Radiography assistants - 15 institutions.

\section{Health Professionals Council}

Other categories of health professional registered by the Nepal Health Professional Council are laboratory technicians, physiotherapists, radiographers plus some other categories. A combined figure of those registered by the Nepal Health Professional Council until the end of May 2013 is as follows:

Nepali Health Professional - 52,404

Foreign Health Professionals - 16.

TOTAL - 52,420

\section{Ayurvedic Council}

The Ayurvedic Council Act took many years to be implemented and the two major grades of workers produced are both by the public sector in institutions run by the government. There are also institutions in the private sector for the training of Homeopathic doctors.

\section{HRH IN PHARMACEUTICAL SCIENCES}

There are 21 colleges with annual intakes of 40 and another eight with annual intake of 20 per annum under the CTEVT doing the three year Diploma with the idea that these personnel would go into the market and man the retail pharmacy sector. This means an annual intake of about 1000 students.

Though the Institute of Medicine had started the manpower training in pharmacy in the seventies, the Bachelor grade manpower had to be trained outside of the country. It was the Kathmandu University, which started the Bachelor, and subsequently Masters in this area. Some years later loM also started training in the Bachelor grade. Following the passage of the Pharmacy Council Act the personnel in these areas had to be registered.

There are currently sixteen colleges under four universities (Tribhuvan University, Kathmandu University, Pokhara University and Purbanchal University) running the Bachelor in Pharmacy programme. A total of 560 students are produced per annum. There are some problems with the Bachelor grade of Pharmacy products. Most are employed in the $45+8$ pharmaceutical industries producing drugs for both human and veterinary consumption.

Thus there has been remarkable development in this field because a large number of institutions have started the production of the 'Bachelor' and Masters grade of manpower.

\section{HUMAN RESOURCES FOR NURSING}

Nepal Government had, during the time of the agreements for setting up medical colleges, stipulated that all such institutions must have a nursing programme of their own. The colleges in their turn have started a number of programmes of both Certificate and Bachelor level. A major producer of PCL nurses is however the CTEVT which has two colleges of its own and hundred and four others affiliated to it. The various nursing programmes and where they are conducted are as shown below: 


\begin{tabular}{|c|c|c|c|c|c|c|c|}
\hline Institution & ANM & PCL & $\begin{array}{c}\text { Post Basic } \\
\text { BN }\end{array}$ & $\begin{array}{c}\text { Post Basic } \\
\text { BNS }\end{array}$ & $\begin{array}{c}\text { BSc } \\
\text { Nursing }\end{array}$ & $\begin{array}{c}\text { MN-Masters } \\
\text { Nursing }\end{array}$ & $\begin{array}{c}\text { MSc } \\
\text { Nursing }\end{array}$ \\
\hline CTEVT & 41 & 102 & & & & & \\
\hline BPKIHS & & 1 & 1 & & 1 & 1 & 1 \\
\hline TU - IoM & & 5 & 8 & & 6 & 3 & \\
\hline Kathmandu University & & (DMI) & & 3 & 9 & & \\
\hline Purbanchal University & & & 21 & & 19 & & \\
\hline Pokhara University & & & & & 2 & & \\
\hline NAMS (Bir Hosp) & & 1 & 1 & & & & \\
\hline TOTAL & 41 & 110 & 31 & 3 & 37 & 4 & 1 \\
\hline
\end{tabular}

Nursing can be taken as an empowerment of women and is important in the context of Nepal. Furthermore one has only to think of Kerala state in India, which improved its health status as a result of the mass interest of girls to take up nursing as a profession. This interest is almost worldwide now. Many have done so in Nepal and are going abroad either as nurses or as care givers in Old Peoples home in North America, Europe or even Australia to provide nursing care to the elderly. This enthusiasm has also furthered the aims of female education in Nepal.

\begin{tabular}{ccc}
\hline Category & End of $\mathbf{2 0 0 4}$ & Up to mid May $\mathbf{2 0 1 3}$ \\
\hline ANMs & 6161 & $20,056^{*}$ \\
\hline NURSES & 5664 & 22038 \\
\hline TOTAL & $\mathbf{1 1 , 8 2 5}$ & $\mathbf{4 2 9 4 4 ^ { * * }}$ \\
\hline
\end{tabular}

* - Currently there is an average of 3560 studying to be ANMs or nurses in Nepal.

** - This includes 750 foreign nurses, registered and working in Nepal

Of this total number of 42,944 , it must be noted that the current renewed status up to $15^{\text {th }}$ May 2013 is:

$\begin{array}{ll}\text { Nurses }-6050 & \text { ANM }-2599 \\ & \text { TOTAL }-8649\end{array}$

The number of nurses working within the country has to be checked and verified. A number of those trained may leave the profession once they get married and have children. The tendency now-a-days, as stated already, is for a number to go abroad to UK, USA, Australia or Canada to work as 'care givers' at old people's homes. It cannot be denied that the private sector has made considerable effort in this. However some questions have been raised as to the quality of training that the girls have received and whether they have done adequate and appropriate on job training.

\section{Physicians \& Dental Surgeons}

Going to the higher grades of medical doctors and dental manpower, the number of Government and private institutions in the country is as follows.

a. Government University / Deemed Universities / PG Institute are the Institute of Medicine, BP Koirala Institute of Health Sciences, Patan Academy of Health Sciences and National Academy of Health Sciences.

b. Private medical colleges under TU are currently the loM plus seven others which includes that run by the Nepal Army. TU does not have a dental college of its own but there is a dental college under BPKIHS at Dharan. The Nepal Army dental college is due to start this year.

c. Private medical colleges under $\mathrm{KU}$ are currently seven plus its own one at Chaukot, Kavre.

d. Dental colleges in the country is the one at BPKIHS, the four private ones under TU and five under KU which includes its own one at Dhulikhel.

The intake of medical and dental students in 2012 was 2025 and 560 respectively as announced by the Nepal Medical Council in Dec. 2012. Of this number about 10\% of the medical students may be foreign and go back to their own countries. Another 10\%- 20\% are free seats given to Nepal Government for scholarship candidates. Currently the rough number of medical and dental student who have to serve the government for two years is about 250 doctors and 50 dental surgeons. One is aware that the government cannot give all of them employment due to various reasons. Besides this about five to six hundred students are going out of the country to study medicine every year.

The number of doctors dental surgeons registered with the Nepal Medical Council at the end of December 2012 was as follows:

\begin{tabular}{ccccc}
\hline No. & Subject & Male & Female & TOTAL \\
\hline 1 & Medical & 7815 & 3544 & 11359 \\
2 & Dental & 507 & 715 & 1222 \\
\hline
\end{tabular}




\section{STATUS OF PG \& SPECIALIST REQUIREMENTS}

One anomaly in all this is the relatively small percentage of slots for PG studies that are being provided by the four PG producing institutions in the country. Furthermore it is difficult to get correct information on the number of candidates admitted therein. A rough guess is 400 but of this a certain percentage will be Indian students who will be going back to their countries after their PG studies in Nepal. This number of about 300 slots for PG studies for Nepalis is very inadequate considering that currently about 1800 new doctors are produced annually in Nepal and about 400 others come back to the country after training elsewhere.

Registration of specialists by Nepal Medical Council till end of 2012 shows a total of 2617 specialists of which 1938 are males and 679 females. A paper by a WHO consultant had documented the distribution of forty-one types of specialists in Nepal in 2003 and forecasted requirements for 2017. The current figures of registered specialists are shown in column six.

\begin{tabular}{|c|c|c|c|c|c|c|c|}
\hline & Specialty & $\begin{array}{c}\text { Nepal } \\
\text { Government } \\
2003 * \text { Estimate }\end{array}$ & $\begin{array}{c}\text { NMC } \\
\text { Reg mid } \\
2006\end{array}$ & $\begin{array}{l}\text { NMC Reg } \\
2007 \text { end }\end{array}$ & $\begin{array}{l}\text { NMC Reg } \\
\text { Dec } 2012\end{array}$ & $\begin{array}{c}\text { Nepal } \\
\text { Government } \\
2017 \text { Projection }\end{array}$ & $\begin{array}{c}\text { Private } \\
\text { Sector } 2017 \\
\text { Projection }\end{array}$ \\
\hline 1 & Anaesthesia & 37 & 43 & 59 & 153 & 62 & 90 \\
\hline 2 & Anatomy & & & & 2 & & \\
\hline 3 & Biochemistry & & & & 1 & & \\
\hline 4 & Cardiology & 16 & 50 & 53 & 77 & 16 & 49 \\
\hline 5 & Clinical Pathology & 44 & 18 & 36 & 101 & 69 & 6 \\
\hline 6 & $\begin{array}{l}\text { Community Medicine/ } \\
\text { Public Health }\end{array}$ & 98 & 11 & 21 & 59 & 106 & 24 \\
\hline 7 & Dental -Masters & & 23 & 43 & 148 & - & $50 \#$ \\
\hline 8 & $\begin{array}{l}\text { Dermatology + Venreal } \\
\text { Disease }\end{array}$ & 17 & 18 & 32 & 81 & 17 & 53 \\
\hline 9 & Endocrinology & 2 & & & & 2 & 1 \\
\hline 10 & ENT \& HNS & 53 & 26 & 39 & 87 & 39 & $60 \#$ \\
\hline 11 & Epidemiology & & & & & 3 & 12 \\
\hline 12 & Forensic Med & - & 3 & 3 & 8 & & $30 \#$ \\
\hline 13 & Gastroenterology & 14 & 11 & 12 & 19 & 6 & 16 \\
\hline $13 \mathrm{~A}$ & General Practice & 30 & 39 & 64 & 144 & 43 & 34 \\
\hline $13 B$ & Family Medicine & & & & 4 & & \\
\hline 15 & General Surgery & 129 & 86 & 144 & 275 & 93 & 145 \\
\hline 16 & Geriatrics & 1 & & & & 1 & 0 \\
\hline 17 & Hepatology & & & & 1 & & \\
\hline 18 & Cardio Thoracic Surgery & 11 & & & & 4 & 12 \\
\hline 19 & Neuro Surgery & 11 & & & & 4 & 12 \\
\hline 20 & Internal Medicine & 118 & 50 & 88 & 277 & 87 & 134 \\
\hline 21 & Tropical Medicine & 11 & & & & 3 & 12 \\
\hline 22 & Microbiology & - & 1 & 2 & 16 & - & $30 \#$ \\
\hline 23 & Nephrology & 8 & 4 & 4 & 10 & 3 & 9 \\
\hline 24 & Neurology & 7 & 7 & 8 & 21 & 3 & 8 \\
\hline 25 & Nuclear Med & 5 & 2 & 3 & 5 & 6 & 0 \\
\hline 26 & $\begin{array}{l}\text { Obstetrics \& } \\
\text { Gynaecology }\end{array}$ & 205 & 115 & 156 & 287 & 140 & 181 \\
\hline 27 & Oncology & - & 3 & 3 & & - & - \\
\hline 28 & Oncosurgery & - & & & 15 & - & - \\
\hline 29 & Ophthalmology & 106 & 43 & 60 & 145 & 44 & 121 \\
\hline 30 & Orthopaedics & 60 & 47 & 95 & 207 & 32 & 68 \\
\hline 31 & Paediatrics & 177 & 84 & 121 & 235 & 129 & 201 \\
\hline
\end{tabular}




\begin{tabular}{|c|c|c|c|c|c|c|c|}
\hline 32 & Paediatric Surgery & 8 & & & & 3 & 9 \\
\hline 33 & Pharmacology & - & 5 & 7 & 19 & $15 \#$ & $15 \#$ \\
\hline 34 & Pulmonology & & & & 1 & & \\
\hline 35 & Psychiatry & 32 & 16 & 25 & 53 & $13 \#$ & $36 \#$ \\
\hline 36 & Physiology & & & & 4 & & \\
\hline 37 & Plastic Surgery & 7 & & & & 3 & 8 \\
\hline 38 & Radiology / Imaging & 59 & 37 & 58 & 135 & 52 & 38 \\
\hline 39 & Radiotherapy & & & & 2 & & \\
\hline 40 & $\begin{array}{l}\text { TB, Respiratory Disease, } \\
\text { Pulmonology. }\end{array}$ & 30 & 4 & 5 & 8 & 11 & 34 \\
\hline 41 & Urology/Urosurgery & 16 & 8 & 9 & 17 & 6 & 18 \\
\hline
\end{tabular}

*-Figures under this column are estimates only of active and retired personnel as per Govt. records.

\# - Estimates required for Medical / Dental Colleges within the country.

Adapted from various sources: Health Sector Support Programme - GTZ/ Nepal and NMC Register

This specialist's number of 2617 as stated already is 1938 male and 679 female. What the current popular specialist choices are Cardiology and Radiology/Radiotherapy, the top five specialities in which doctors registered with the Nepal Medical as specialists till the end of December 2012 were:
1. Obstetrics \& Gynaecology
287
2. Internal Medicine
3. General Surgery
4. Paediatrics
5. Anaesthesia
6. MDGP
7. Clinical Pathology
101

Because of the establishment of medical and dental colleges in Nepal, the number of specialists has increased markedly. Specialists in Basic Science subjects are being trained but slowly because of the dearth of candidates prepared to enter in these fields. Though BPKIHS had allowed dental graduates for MD/ MS in Basic Sciences as from late 1990's, it was only from 2010 after KU started allowing and admitting BDS graduates for Masters in Basic Science subjects that more interest has been generated in this field.

It is difficult to say what percentage of doctors who are specialists work in the Public or Private sector. The fact is that a substantial number work in both sectors. Government employed doctors have always been allowed to do practice in out of hospital hours.

There is an increasing demand for specialist services at Regional, Sub-regional and Zonal Hospitals. There are no specialists in the district hospitals except for the MDGP who too must be accepted as a specialist in his field.
Because of the establishment of medical colleges out of Kathmandu valley specialist services have gradually sprung up elsewhere. However because of the lack of specialists at district level, the government is planning to provide this service with the help of the medical colleges in the country. The idea is that each medical college will go and provide specialist services at one or two districts adopted by them. The government will give funds for this purpose.

What one can deduce from these figures is that, as these estimates have been made following discussions of various multi or bilateral agencies but adequate representation of the private sector was not there. The figures of registered specialists at the end of 2007as shown in column five does not reflect the requirements of medical, dental colleges, community hospitals and nursing homes. A fresh manpower requirements exercise has to be done as early as possible if realistic and meaningful figures are to be obtained. The five existing councils viz. NMC, NNC, HPC, PC and AC have all at times played a commendable role in setting up standards for training but now must be made to ensure a corrected and updated record of registration. Only on the basis of current information can the country ascertain what the status is and what should be done to correct it. This is essential if we are to improve.

\section{CONCLUSION}

The initial HRH production units of 1934 for basic level workers were upgraded, with the introduction of the New Education System Plan in 1972, to train middle level workers at the Institute of Medicine. After the implementation of the New Education System Plan (NESP) the production of all levels of HRH became a responsibility of the Ministry of Education. As from 1978 
the loM started the training of doctors and from 1982 the training of General Practice specialists named MDGP. Specialisations in other areas were started later. In the subsequent years after this a number of institutions have come up for the training of $\mathrm{HRH}$ of various grades.

There have been mismatches in the production of categories of manpower. The case of physiotherapists is worth mentioning to illustrate the lack of adequate planning. The First Long Term Health Plan (1960-75) had projected a demand of 120 physiotherapists when the certificate level course was started but a situation occurred when the manpower produced could not get jobs. Some years later KU started both Certificate and Bachelor level courses. Pharmacy personnel have also been discussed as a lot for ' over the counter sales' of medicine or 'self-treatment' is in vogue in many parts of the country. As doctors are not available everywhere they are providing a service but at what cost. The easy availability of habituating drugs and the misuse of antibiotics have created new problems which have to be tackled before they get out of hand.

Though some experts may disagree, I feel that the positive aspect of increased $\mathrm{HRH}$ production is that the health of the people of Nepal has improved. All the vital statistics of the country, as supplied by the MoHP to the various agencies that compile this data bear this out. One presumes that these figures are by and large correct. Nepal has been recognised as being on track for the attainment of the Millennium Development Goals (MDG) on maternal and child health. This is all because of increased and better services in the country. Now that health will be enshrined as a birthright of the people within the new constitution, one can hope that the future for the Nepali citizen is bright. The negative aspect however is that as $81 \%$ of the population reside in the rural areas, the health services may not be easily accessible to a substantial number of people. Most of the health services are concentrated in the urban centres where only $19 \%$ of the people live.

\section{ACKNOWLEDGEMENTS}

I would like to thank Dr. Nil Mani Upadhayay and Ms Anita Lama of Nepal Medical Council for providing me the latest figures of doctors, dental surgeons and specialists registered there. Also to Prof. Dr. Ramesh Adhikari for giving me some feedback. My thanks are also to Mr. Nirmal Bista, Mr. Sanjay Mani Dixit, Mr. Kumar Pant, Mr.Narayan Subedi, Mrs Sushila Acharya and Ms Bindu Phuyal who have helped me in my search for further relevant information.

\section{REFERENCES}

1. Dixit H. Nepal's Quest for Health. 3rd ed. Kathmandu: Educational Publishing House; 2005.

2. Ministry of Health (Nepal). Strategic plan for human resources for health, 2003-2017. Kathmandu: Ministry of Health; 2003.

3. World Health Organization. World Health Report 2006, Working together for health. Geneva: WHO; 2006.
4. Nepal Public Health Foundation. Situational analysis of human resources for health. Kathmandu: Nepal Public Health Foundation.

5. Ministry of Health and Population (Nepal). National situation analysis on human resources for health, 2012. Kathmandu: Ministry of Health and Population; 2013. 